\title{
SISTEM PENDUKUNG KEPUTUSAN PENILAIAN KARYAWAN TERBAIK MENGGUNAKAN METODE SIMPLE ADDITIVE WEIGHTING PADA PT. TRANS RETAIL INDONESIA
}

\author{
Liesnaningsih ${ }^{1}$, Oklawati ${ }^{2}$, Dian Kasoni ${ }^{3}$ \\ Universitas Muhammadiyah Tangerang/Fakultas Teknik \\ Program Studi Informatika \\ Jl. Perintis Kemerdekaan 1/33 Cikokol Kota Tangerang TLP.55793251, 55772949, 55793802 \\ liesnaningsih@gmail.com¹, Okla.afattah@gmail.com², dhekalearning@gmail.com³
}

\begin{abstract}
Abstrak, Pengelolaan sumber daya manusia (SDM) suatu perusahaan sangat mempengaruhi banyak aspek penentu keberhasilan kerja perusahaan. Salah satu yang terpenting dalam menajeman sumber daya manusia (SDM) di suatu perusahaan adalah pemilihan karyawan terbaik secara periodik untuk memacu semangat karyawan dalam meningkatkan dedikasi dan kinerjanya. Pada PT. Trans Retail Indonesia saat ini belum optimal dalam pelaksanaan pemilihan karyawan terbaik, hal ini disebabkan karena belum tersedianya media yang dapat memproses penilaian karyawan dan memberikan rekomendasi dalam penilaian karyawan terbaik. Penelitian ini bertujuan untuk mengetahui prosedur penilaian dan pemilihan karyawan terbaik pada PT. Trans Retail Indonesia, serta untuk menghasilkan sistem pendukung keputusan penilaian karyawan terbaik berdasarkan kebutuhan perusahaan. Sistem pendukung keputusan akan dibuat menggunakan metode Simple Additive Weighting (SAW) dengan kriteria-kriteria yang sudah digunakan PT. Trans Retail Indonesia yaitu kejujuran, taat peraturan, mangkir/alpha, kedisiplinan, tanggung jawab, kebersihan, kerajinan, kreatifitas, kerjasama dan senyuman. Sistem pendukung keputusan dikembangkan dengan bahasa pemrograman PHP dan MySQL. Output dari sistem ini adalah nilai perhitungan pemilihan karyawan terbaik dan rekomendasi karyawan terbaik PT. Trans Retail Indonesia.
\end{abstract}

Kata kunci: Sistem Pendukung Keputusan, Simple Additive Weighting (SAW), Pemilihan, Penilaian, Karyawan Terbaik.

Abstract, Management of human resources (HR) of a company greatly influences many aspects that determine the success of a company's work. One of the most important in the management of human resources (HR) in a company is the periodic selection of the best employees to stimulate employee morale in increasing their dedication and performance. At PT. Trans Retail Indonesia is currently not optimal in the implementation of the best employee selection, this is due to the unavailability of media that can process employee assessments and provide recommendations in the assessment of the best employees. This study aims to determine the best employee assessment and selection procedures at PT. Trans Retail Indonesia, as well as to produce the best employee assessment decision support system based on company needs. Decision support system will be made using the Simple Additive Weighting (SAW) method with criteria that have been used by PT. Trans Retail Indonesia, namely honesty, obeying rules, defaulting / alpha, discipline, responsibility, cleanliness, crafts, creativity, cooperation and smiles. Decision support system was developed with PHP and MySQL programming languages. The output of this system is the calculation value of the best employee selection and the best employee recommendation of PT. Trans Retail Indonesia.

Keywords: Decision Support System, Simple Additive Weighting (SAW), Selection, Assessment, Best Employees. 


\section{PENDAHULUAN}

\subsection{Latar belakang}

Salah satu elemen dalam perusahaan yang sangat penting adalah Sumber Daya Manusia (SDM). Pengelolaan SDM dari suatu perusahaan sangat mempengaruhi banyak aspek penentu keberhasilan kerja dari perusahaan tersebut. Jika SDM dapat diorganisir dengan baik, maka diharapkan perusahaan dapat menjalankan semua proses usahanya dengan baik. PT. Trans Retail Indonesia melakukan penilaian karyawan terbaik untuk memacu semangat karyawan dalam meningkatkan dedikasi dan kinerjanya, Penilaian karyawan terbaik dilakukan secara periodik akan tetapi belum optimal dalam pelaksanannya. PT. Trans Retail Indonesia mendapat kendala dalam memutuskan karyawan yang akan diprioritaskan. Kendala yang dihadapi adalah manager SDM tidak menggunakan metode yang dapat menangani permasalahan prioritas dengan banyak kriteria. Selain itu, sering kali SDM kesulitan memilih karyawan terbaik dikarenakan banyaknya karyawan yang dinilai. Hal ini menjadi permasalahan untuk menentukan tepat atau tidaknya seseorang terpilih sebagai karyawan terbaik.

\subsection{Tujuan Penlitian}

Tujuan penelitian ini adalah:

1. Membangun sistem pendukung keputusan dengan menggunakan metode simple additive weighting (SAW) untuk menentukan penilaian karyawan terbaik.

2. Menerapkan metode Simple additive Weighting (SAW) sebagai salah satu metode pemecahan masalah dengan membuat sistem pendukung keputusan berbasis model SAW tersebut.

3. Untuk memperkecil kemungkinan terjadinya kesalahan, melalui hasil penilaian yang dilakukan.

\subsection{Batasan masalah}

Berdasarkan latar belakang dan perumusan masalah yang telah diuraikan, agar pembahasan dalam penelitian ini tidak meluas, maka dibatasi dengan hal-hal berikut:

1. Aplikasi sistem pendukung keputusan dibuat dengan menggunakan metode Simple additive weighting (SAW);

2. Sistem yang dibuat merupakan pendukung keputusan saja, sehingga keputusan sesungguhnya yang diambil tetap berada pada Manager SDM;

3. Kriteria yang digunakan dalam penelitian menyesuaikan dengan internal maupun prosedur perusahaan.

\section{TINJAUAN PUSTAKA}

\subsection{Sistem Pendukung Keputusan}

Setiap pendukung keputusan merupakan proses alternatif tindakan untuk mencapai tujuan atau sasaran tertentu. Sistem pendukung keputusan dilakukan dengan pendekatan sistematis terhadap permasalahan melalui proses pengumpulan data menjadi informasi, serta ditambah dengan faktor-faktor yang perlu dipertimbangkan dalam sebuah keputusan.

\subsection{Simple Additive Weighting (SAW)}

Metode SAW sering juga dikenalkan dengan istilah metode penjumlahan terbobot. Konsep dasar SAW adalah mencari penjumlahan terbobot dari kinerja setiap alternatif pada semua atribut metode SAW membutuhkan proses normalisasi matriks keputusan (X) ke suatu skala yang dapat dibandingkan dengan semua rating alternatif yang ada.

$$
\left\{\begin{array}{l}
\frac{x_{i j}}{\max x_{i j}} \\
\frac{\min x_{i j}}{x_{i j}}
\end{array}\right.
$$

Jika $\mathrm{j}$ adalah atribut keuntunggan (benefit) Jika j adalah atribut biaya (cost)

Dimana :

Rij : Rating kinerja ternomalisasi

Maxi : Nilai maksimum dari setiap baris dan kolom

Mini : Nilai minimum dari setiap baris dan kolom

Xij : Baris dan kolom dari matriks

Dimana rij adalah kinerja ternormalisasi dari alternnatif Ai pada atribut $\mathrm{Cji}=1,1 \ldots, \mathrm{m}$ dan $\mathrm{j}=$ $1,2 \ldots, \mathrm{m}$. Nilai preferensi altternatif $(\mathrm{Vi})$ diberikan sebagai :

$$
V_{i=\sum_{j=i}^{n} w j r i j}
$$

Dimana :

$\mathrm{Vi} \quad$ : Nilai Akhir Alternatif

$\mathrm{Wi}$ : Bobot yang telah ditentukan

Rij : Normalisasi matriks 
Nilai $\mathrm{V}$ yang lebih besar, mengindikasikan bahwa alternatif Ai lebih terpilih.

\subsection{Unifield Modeling Languange}

UML (Unified Modeling Language) adalah bahasa pemodelan untuk sistem atau perangkat lunak yang berparadigma (berorientasi objek). Pemodelan sesungguhnya digunakan untuk penyederhanaan permasalahan-permasalahan yang kompleks sedemikian rupa sehingga lebih mudah dipelajari dan dipahami.

\section{METODOLOGI PENELITIAN}

\subsection{Metode Pengumpulan Data}

Dalam menyelesaikan skripsi ini, baik dalam pengumpulan data maupun informasi yang diperlukan untuk mendapatkan kebenaran materi uraian pembahasan, penulis memperoleh data yang diinginkan melalui pengumpulan data dengan metode pengumpulan data yang terdiri dari :

1. Metode Observasi

Penulis melakukan observasi secara langsung ke tempat, untuk mempelajari dan mendapatkan informasi seputar penilaian karyawan terbaik di PT. Trans Retail indonesia cabang Bogor. Tujuan dilakukannya observasi adalah guna mengetahui bagaimana jalannya sistem berjalan saat ini dan mengetahui masalahmasalah apa saja yang terjadi pada sistem berjalan. Kemudian, dari masalah yang didapat, dapat dianalisis sistem seperti apa yang akan dirancang guna membantu jalannya proses penilaian karyawan PT. Trans Retail Indonesia.

2. Metode Wawancara

Metode ini dilakukan dengan mewawancarai seseorang yang ahli dalam bidangnya. Pewawancara melakukan wawancara kepada narasumber Ibu Suci Rahmadona (Manager SDM) Transmart Bogor Yasmi, untuk memperoleh data-data yang diperlukan dalam pembuatan aplikasi penilaian karyawan.

3. Studi Pustaka

Dalam melakukan studi pustaka penulis melengkapi kekurangan-kekurangan data yang diperoleh dari studi lapangan. Pengumpulan data dengan cara mengambil dari sumber-sumber media cetak maupun elektronik yang dapat dijadikan acuan pembahasan masalah. Penulis membaca dan mempelajari buku-buku dan situs yang penulis kunjungi dapat dilihat pada daftar pustaka.

\subsection{Metode Analisa dan Perancangan}

Sebagaimana yang telah diuraikan pada bab satu, dalam Rancang Bangun Sistem Pendukung Keputusan Penilaian Karyawan Terbaik di PT, Trans Retail Indonesia Berbasis Web. Penulis menggunakan metode pengembangan sistem dengan model proses SDLC Waterfall. Yang merupakan model klasik sederhana, terstruktur dan bersifat sekuensial linear, karena prosesnya mengalir begitu saja, mulai dari awal hingga akhir.

Dalam pengembangannya metode Waterfall memiliki beberapa tahapan yang berurutan yaitu

1. Analisis kebutuhan sistem (Penilaian)

2. Desain sistem (Design system)

3. Pengkodean (coding)

4. Pengujian (Testing)

\subsection{Analisa Kebutuhan Sistem (penilaian)}

Analisa sistem merupakan suatu tahap pemahaman proses yang bertujuan untuk mengetahui proses apa saja yang terlibat dalam sistem dan berhubungan satu proses dengan proses lainnya. Dari pemahaman proses tersebut maka dapat dilakukan suatu evaluasi dan usulan terhadap sistem yang ada, untuk dikembangkan labih lanjut.

Proses menganalisis dan pengumpulan kebutuhan sistem yang sesuai dengan domain informasi tingkah laku, unjuk kerja, dan antar muka (interface) yang diperlukan.

\section{HASIL DAN PEMBAHASAN}

\subsection{Analisa Kebuttuhan Sistem}

Kebutuhan sistem ini meliputi kebutuhan data, hardware dan software. Kebutuhan data yaitu data-data yang diperlukan dalam penelitian ini yaitu antara lain:

1. Data pribadi karyawan pada PT. Trans retail Indonesia yang nantinya akan menjadi perhitungan.

2. Kriteria-kriteria yang telah ditentukan sebelumnya.

3. Bobot untuk setiap kriteria yang telah ditentukan, dan nantinya akan bisa berubah sesuai dengan kebijakan dari perusahaan.

Kriteria-kriteria yang digunakan dalam penelitian ini adalah sebagai berikut:

C1: Pengetahuan 
C2 : Kepribadian

C3 : Kejujuran

C4 : Kepemimpinan

C5 : Kedisiplinan

Dari tingkat kepentingan dari setiap kriteria, dinilai dari tingkat 1 sampai 5 sebagai berikut:

1 : Sangat Kurang

2 : Kurang

3 : Cukup

4 : Baik

5 : Sangat baik

4.2. Olah Data dan Perhitungan Manual

Pada tahap penilaian ini akan dilakukan perhitungan terhadap sistem yang dibangun dengan menggunakan metode SAW yang digunakan untuk pengolahan data penilaian karyawan terbaik.

Kriteria :

C1: Pengetahuan (benefit)

C2 : Kepribadian (benefit)

C3 : Kejujuran (benefit)

C4 : Kepemimpinan (cost)

C5 : Kedisiplinan (cost)

Alternatif :

A1 : Achmad Reza Kurniawan

A2 : Wilda ditria

A3 : Kurlaing Santoso

A4 : Yodi Listandi

A5 : Widya Nur

A6 : Suci Romadhona

A7 : Nicky Firdaus

Tabel 1. Data Penilaian

\begin{tabular}{|c|c|c|c|c|c|}
\hline \multirow{2}{*}{ Alternatif } & \multicolumn{5}{|c|}{ Kriteria } \\
\cline { 2 - 6 } & C1 & C2 & C3 & C4 & C5 \\
\hline A1 & 1 & 4 & 4 & 3 & 2 \\
\hline A2 & 2 & 3 & 4 & 3 & 2 \\
\hline A3 & 1 & 4 & 4 & 3 & 2 \\
\hline A4 & 1 & 4 & 3 & 4 & 1 \\
\hline A5 & 1 & 4 & 4 & 3 & 4 \\
\hline A6 & 1 & 2 & 3 & 1 & 1 \\
\hline A7 & 2 & 1 & 3 & 5 & 3 \\
\hline
\end{tabular}

Berdasarkan Tabel di atas, dapat dibentuk matriks keputusan $\mathrm{X}$ sebagai berikut:

$$
\times=\left[\begin{array}{lllll}
1 & 4 & 4 & 3 & 2 \\
2 & 3 & 4 & 3 & 2 \\
1 & 4 & 4 & 3 & 2 \\
1 & 4 & 3 & 4 & 1 \\
1 & 4 & 4 & 3 & 4 \\
1 & 2 & 3 & 1 & 1 \\
2 & 1 & 3 & 5 & 3
\end{array}\right]
$$

Memberikan Nilai bobot (W) Untuk menentukan bobot pada divisi desain di bentuk dalam table di bawah ini :

Tabel 2. Bobot divisi desain

\begin{tabular}{|c|c|}
\hline Kriteria & Bobot \\
\hline C1 & 30 \\
\hline C2 & 25 \\
\hline C2 & 15 \\
\hline C4 & 20 \\
\hline C5 & 10 \\
\hline
\end{tabular}

$$
W=[30,25,15,20,10]
$$

Normalisasi :

a. Kriteria Pengetahuan, termasuk atribut keuntungan (benefit)

$$
\begin{aligned}
& \mathrm{R} 11=\frac{1}{\max (1 ; 2 ; 1 ; 1 ; 1 ; 1 ; 2)}=\frac{1}{2}=0.5 \\
& \mathrm{R} 21=\frac{2}{\max (1 ; 2 ; 1 ; 1 ; 1 ; 1 ; 2)}=\frac{2}{2}=1 \\
& \mathrm{R} 31=\frac{1}{\max (1 ; 2 ; 1 ; 1 ; 1 ; 1 ; 2)}=\frac{1}{2}=0.5 \\
& \mathrm{R} 41=\frac{1}{\max (1 ; 2 ; 1 ; 1 ; 1 ; 1 ; 2)}=\frac{1}{2}=0.5 \\
& \mathrm{R} 51=\frac{1}{\max (1 ; 2 ; 1 ; 1 ; 1 ; 1 ; 2)}=\frac{1}{2}=0.5 \\
& \mathrm{R} 61=\frac{1}{\max (1 ; 2 ; 1 ; 1 ; 1 ; 1 ; 2)}=\frac{1}{2}=0.5 \\
& \mathrm{R} 71=\frac{2}{\max (1 ; 2 ; 1 ; 1 ; 1 ; 1 ; 2)}=\frac{2}{2}=1
\end{aligned}
$$

b. Kriteria Kepribadian, termasuk atribut keuntungan (benefit)

$$
\begin{aligned}
& \mathrm{R} 12=\frac{4}{\max (4 ; 3 ; 4 ; 4 ; 4 ; 2 ; 1)}=\frac{4}{4}=1 \\
& \mathrm{R} 22=\frac{3}{\max (4 ; 3 ; 4 ; 4 ; 4 ; 2 ; 1)}=\frac{3}{4}=0.75 \\
& \mathrm{R} 32=\frac{4}{\max (4 ; 3 ; 4 ; 4 ; 4 ; 2 ; 1)}=\frac{4}{4}=1 \\
& \mathrm{R} 42=\frac{4}{\max (4 ; 3 ; 4 ; 4 ; 4 ; 2 ; 1)}=\frac{4}{4}=1
\end{aligned}
$$




$$
\begin{aligned}
& \mathrm{R} 52=\frac{4}{\max (4 ; 3 ; 4 ; 4 ; 4 ; 2 ; 1)}=\frac{4}{4}=1 \\
& \mathrm{R} 62=\frac{2}{\max (4 ; 3 ; 4 ; 4 ; 4 ; 2 ; 1)}=\frac{2}{4}=0.5 \\
& \mathrm{R} 72=\frac{1}{\max (4 ; 3 ; 4 ; 4 ; 4 ; 2 ; 1)}=\frac{1}{4}=0.25
\end{aligned}
$$

c. Kriteria Kejujuran, termasuk atribut keuntungan (benefit)

$$
\begin{aligned}
& \mathrm{R} 13=\frac{4}{\max (4 ; 4 ; 4 ; 3 ; 4 ; 3 ; 3)}=\frac{4}{4}=1 \\
& \mathrm{R} 23=\frac{4}{\max (4 ; 4 ; 4 ; 3 ; 4 ; 3 ; 3)}=\frac{4}{4}=1 \\
& \mathrm{R} 33=\frac{4}{\max (4 ; 4 ; 4 ; 3 ; 4 ; 3 ; 3)}=\frac{4}{4}=1 \\
& \mathrm{R} 43=\frac{3}{\max (4 ; 4 ; 4 ; 3 ; 4 ; 3 ; 3)}=\frac{3}{4}=0.75 \\
& \mathrm{R} 53=\frac{4}{\max (4 ; 4 ; 4 ; 3 ; 4 ; 3 ; 3)}=\frac{4}{4}=1 \\
& \mathrm{R} 63=\frac{3}{\max (4 ; 4 ; 4 ; 3 ; 4 ; 3 ; 3)}=\frac{3}{4}=0.75 \\
& \mathrm{R} 73=\frac{3}{\max (4 ; 4 ; 4 ; 3 ; 4 ; 3 ; 3)}=\frac{3}{4}=0.75
\end{aligned}
$$

d. Kriteria Kepemimpinan, termasuk atribut biaya (cost)

$$
\begin{aligned}
& \mathrm{R} 14=\frac{\min (3 ; 3 ; 3 ; 4 ; 3 ; 1 ; 5)}{3}=\frac{1}{3}=0.33 \\
& \mathrm{R} 24=\frac{\min (3 ; 3 ; 3 ; 4 ; 3 ; 1 ; 5)}{3}=\frac{1}{3}=0.33 \\
& \mathrm{R} 34=\frac{\min (3 ; 3 ; 3 ; 4 ; 3 ; 1 ; 5)}{3}=\frac{1}{3}=0.33 \\
& \mathrm{R} 44=\frac{\min (3 ; 3 ; 3 ; 4 ; 3 ; 1 ; 5)}{4}=\frac{1}{4}=0.25 \\
& \mathrm{R} 54=\frac{\min (3 ; 3 ; 3 ; 4 ; 3 ; 1 ; 5)}{3}=\frac{1}{3}=0.33 \\
& \mathrm{R} 64=\frac{\min (3 ; 3 ; 3 ; 4 ; 3 ; 1 ; 5)}{1}=\frac{1}{1}=1 \\
& \mathrm{R} 74=\frac{\min (3 ; 3 ; 3 ; 4 ; 3 ; 1 ; 5)}{5}=\frac{1}{5}=0.2
\end{aligned}
$$

e. Kriteria Kedisiplinan, termasuk atribut biaya (cost)

$$
\begin{aligned}
& \mathrm{R} 15=\frac{\min (2 ; 2 ; 2 ; 1 ; 4 ; 1 ; 3)}{2}=\frac{1}{2}=0.5 \\
& \mathrm{R} 25=\frac{\min (2 ; 2 ; 2 ; 1 ; 4 ; 1 ; 3)}{2}=\frac{1}{2}=0.5 \\
& \mathrm{R} 35=\frac{\min (2 ; 2 ; 2 ; 1 ; 4 ; 1 ; 3)}{2}=\frac{1}{2}=0.5 \\
& \mathrm{R} 45=\frac{\min (2 ; 2 ; 2 ; 1 ; 4 ; 1 ; 3)}{1}=\frac{1}{1}=1 \\
& \mathrm{R} 55=\frac{\min (2 ; 2 ; 2 ; 1 ; 4 ; 1 ; 3)}{4}=\frac{1}{4}=0.25 \\
& \mathrm{R} 65=\frac{\min (2 ; 2 ; 2 ; 1 ; 4 ; 1 ; 3)}{1}=\frac{1}{1}=1 \\
& \mathrm{R} 75=\frac{\min (2 ; 2 ; 2 ; 1 ; 4 ; 1 ; 3)}{3}=\frac{1}{3}=0.33
\end{aligned}
$$

Dari persamaan normalisasi matriks $\mathrm{X}$ di peroleh matriks $\mathrm{R}$ sebagai berikut :

$$
R=\left[\begin{array}{ccccc}
0.5 & 1 & 1 & 0.33 & 0.5 \\
1 & 0.75 & 1 & 0.33 & 0.5 \\
0.5 & 1 & 1 & 0.33 & 0.5 \\
0.5 & 1 & 0.75 & 0.25 & 1 \\
0.5 & 1 & 1 & 0.33 & 0.25 \\
0.5 & 0.5 & 0.75 & 1 & 1 \\
1 & 0.25 & 0.75 & 0.2 & 0.33
\end{array}\right]
$$

Melakukan proses perangkingan dengan menggunakan bobot yang telah diberikan oleh pengambil keputusan $W=[30,25,15,20,10]$

$$
V_{i}=\sum_{j=1}^{V_{i}} w_{j} r_{i j}
$$

Keterangan :

$V_{i}=$ Rangking untuk setiap alternatif $\mathrm{w}_{\mathrm{j}}=$ Nilai bobot dari setiap kriteria $r_{i j}=$ Nilai rating kinerja ternormalisasi

Nilai $\mathrm{Vi}$ yang lebih besar mengindikasikan bahwa alternatif Ai lebih terpilih.

$$
\begin{array}{ll}
\mathrm{V}_{1}=\quad \begin{array}{l}
(30)(0.5)+(25)(1)+(15)(1)+ \\
(20)(0.33)+(10)(0.5)=66.66
\end{array} \\
\mathrm{~V}_{2}=\begin{array}{l}
(30)(1)+(25)(0.75)+(15)(1)+ \\
(20)(0.33)+(10)(0.5)=75.41
\end{array} \\
\mathrm{~V}_{3}=\begin{array}{l}
(30)(0.5)+(25)(1)+(15)(1)+ \\
(20)(0.33)+(10)(0.5)=66.66
\end{array} \\
\mathrm{~V}_{4}=\begin{array}{l}
(30)(0.5)+(25)(1)+(15)(0.75)+ \\
(20)(0.25)+(10)(1)=66.25
\end{array} \\
\mathrm{~V}_{5}=\begin{array}{l}
(30)(0.5)+(25)(1)+(15)(1)+ \\
(20)(0.33)+(10)(0.25)=64.16
\end{array} \\
\mathrm{~V}_{6}=\quad \begin{array}{l}
(30)(0.5)+(25)(0.5)+(15)(0.75)+ \\
(20)(1)+(10)(1)=68.75
\end{array} \\
\mathrm{~V}_{7}=\begin{array}{l}
(30)(1)+(25)(0.25)+(15)(0.75)+ \\
(20)(0.2)+(10)(0.33)=54.83
\end{array}
\end{array}
$$

Kesimpulan, yang terpilih untuk diterima sebagai karyawan terbaik adalah $V_{2}$ yaitu Wilda Ditria $\left(A_{2}\right)$ karena memiliki nilai freperensi yang lebih tinggi dibandingkan dengan yang lain.

\subsection{Perancangan Sistem}


Berdasarkan analisa pada sistem yang proses yang sedang berjalan pada sistem pendukung keputusan penilaian karyawan PT. Trans Retail Indonesia, maka selanjutnya akan dibahas mengenai rancangan usulan sistem yang akan di bangun. Ada beberapa prosedur sistem usulan yang digunakan dalam pembangunan sistem penilaian karyawan terbaik ini, diantaranya agar sistem diharapkan mampu merubah proses penilain, penentuan karyawan yang memenuhi standar perhitungan, dari manual menjadi terkomputerisasi sehingga mempercepat informasi yang dihasilkan.

Rancangan sistem bertujuan untuk memperbaiki sistem yang lama dengan memberi gambaran atau pandangan yang jelas menurut proses rancangan sistem dari awal penilaian hingga akhir penilaian. Dalam menganalisa usulan prosedur yang baru pada penilaian ini menggunakan diagram use case sebagai berikut.

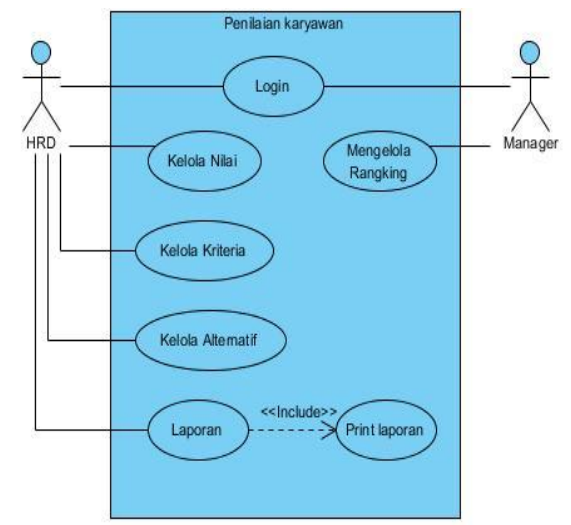

Gambar 1. Usecase Penilaian Karyawan

Berikut adalah implementasi halaman pengguna:

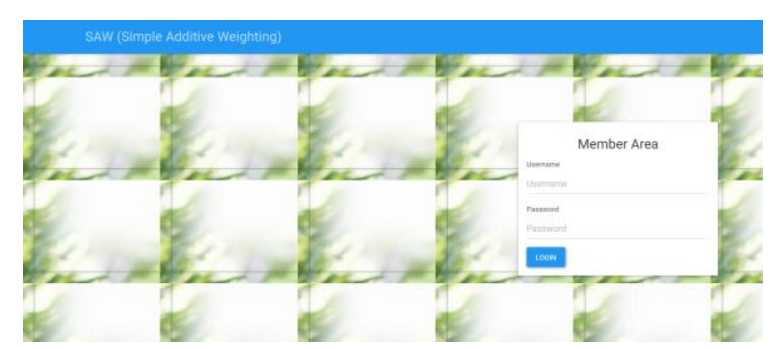

Gambar 2. Tampilan Menu Login

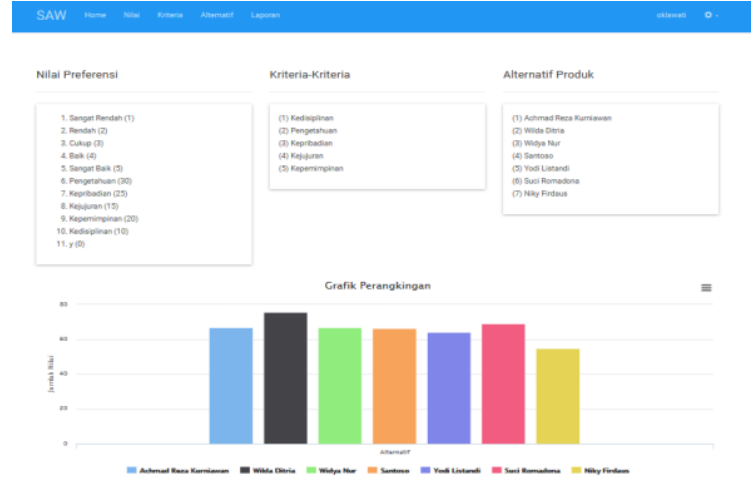

Gambar 3. Tampilan Menu Home

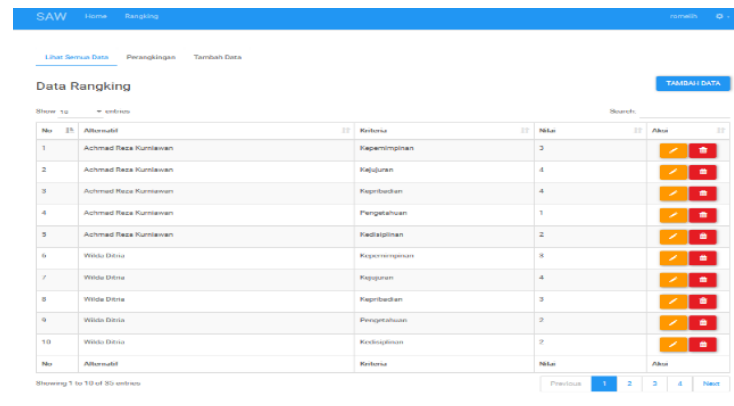

Gambar 4. Tampilan Menu Rangking

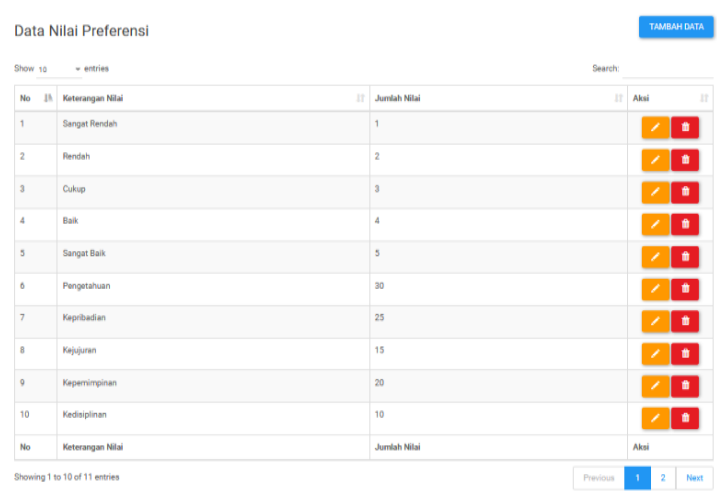

Gambar 5. Tampilan Menu Nilai

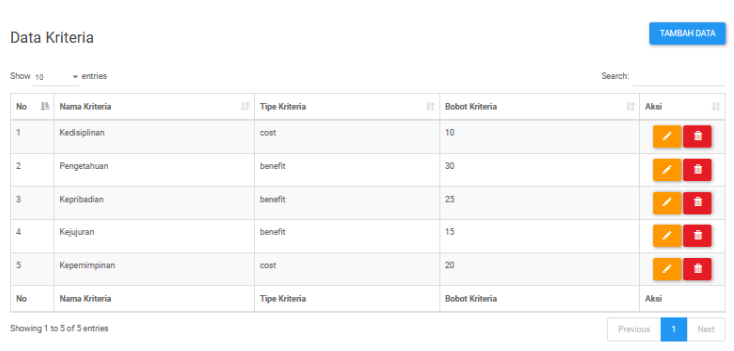

Gambar 6. Tampilan Menu Kriteria 


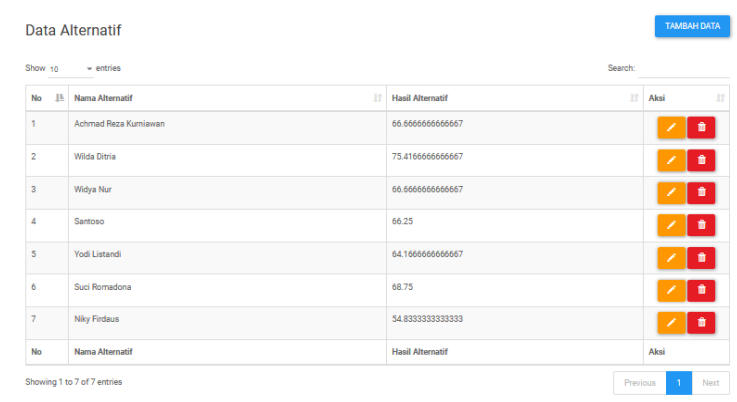

Gambar 7. Tampilan Menu Alternatif

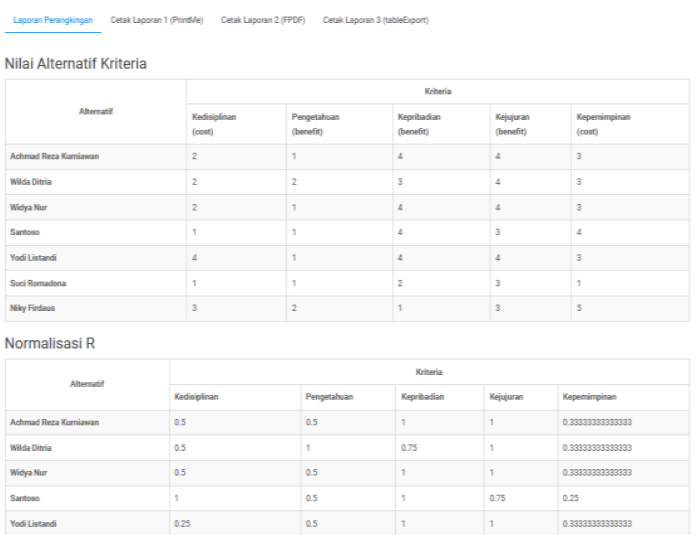

Gambar 8. Tampilan Menu Laporan

\section{KESIMPULAN DAN SARAN}

\subsection{Kesimpulan}

Dari hasil penelitian ilmiah di PT. Trans Retail Indonesia, dengan analisis dan pembahasan yang sedang berjalan pada rancangan sistem ini diantaranya :

1. Pembuatan laporan dan pencarian data akan lebih terintegarasi jika dilakukan dengan sistem terkomputerisasi sehingga waktu yang dibutuhkan akan menjadi lebih efisien.

2. Pembuatan sistem yang terkomputerisasi dalam pengolahan data karyawan bisa lebih cepat dan mengurangi kesalahan dalam proses pencatatan data.

3. Dengan adanya sistem ini, memudahkan manager dalam melakukan proses penilaian karyawan dan pengeluaran nilai sangat cepat dan akurat.

\subsection{Saran}

Saran-saran yang dapat dikemukakan sebagai bahan pertimbangan agar rancangan lebih optimal, maka penulis memberikan saran, yaitu :

1. Melakukan backup dan update data secara berkala agar apabila terjadi kerusakan pada sistem, data-data yang ada tidak hilang.

2. Membuat perhitungan baru pada sistem pendukung keputusan menggunakan metode SAW dengan model fuzzy

3. Melakukan update prosedur untuk kriteria yang baru agar kriteria lebih meluas.

\section{REFERENSI}

[1] Febrina Sari, 2017. Metode dalam pengambilan keputusan.Yogyakarta :Pendidikan Deepublish.

[2]Henry, W. 2009. Sistem pendukung keput usan untuk menentukan penerimaan beasiswa bank BRI menggunakan FMADM (studi kasus: mahasiswa fakultas tehnologi industry Universitas Islam Indonesia).

[3] Jogiyanto, 2005.Pendekatan sistem yang lebih menekankan pada elemen-elemen yang

berintegrasi untuk mencapai tujuan tertentu.

[4] Kendall dan Kendall 2006. Sistem adalah serangkaian subsistem yang saling terkait dan tergantung satu sama lainnya, bekerja bersama-sama untuk mencapai tujuan dan sasaran yang sudah ditetapkan sebelumnya

[5] (2002) The IEEE website. [Online]. Available: http://www.iee.org/

[6] Kusumadewi, Sri., Hartati, S., Harjoko, A., dan Wardoyo, R. (2006). Fuzzy MultiAttribute

[7] Rosa A.S dan M Shalahuddin. 2018. Rekayasa Perangkat Lunak. Bandung : Informatika.

[8] Turban, dan Nofriansyah 2014.Sistem Pendukung Keputusan biasanya dibangun untuk mendukung solusi atau sebuah masalah atau suatu peluang. 